\title{
Student ratings to evaluate the teaching effectiveness: Factors should be considered
}

\section{Marcelo Machado De Luca de Oliveira Ribeiro, Lia Alencar Coelho}

Faculty of Animal Science and Food Engineering, University of São Paulo, Brazil.

\begin{abstract}
The study discusses the student ratings of a professor teaching sociology disciplines in different undergraduate courses. The data were obtained from questionnaires consisting of a series of inquiries about the discipline, focusing on how it fits in the curricular structure (discipline evaluation) and, also, on teacher's performance (professor evaluation). A total of 480 students answered the questionnaire and, for each question they had a total of five possible answers: very poor (1 point), poor (2 points), fair (3 points), good (4 points) and excellent (5 points). Considering discipline and professor evaluations, students from Animal Science, Food Engineering and Veterinary Medicine courses consider "fair" the performance of the sociology professor. Regarding to the professor evaluation, the students of the three undergraduate courses considered the performance of the teacher "good". For discipline evaluation, the Animal Science and Veterinary Medicine students considered the discipline "fair" and the Food Engineering students considered the discipline "poor". The results obtained can serve as a basis for the design of a institutional evaluation system of teaching based on student ratings, however the evaluation of the discipline and the performance of the teacher must be considered separately.
\end{abstract}

Keywords: course evaluation; higher education; teaching evaluation. 


\section{Introduction}

Student evaluation of teaching has an important role when it comes to measuring the quality of high-level education and it has been used as one of the most important indicators of teaching effectiveness (Kulik, 2001). As a rule, gathering feedback from students through questionnaires (Serrano \& Rueda, 2001) is a frequently used method in most universities around the globe and it has been generally accepted by those involved. However, once this method is adopted, some criteria must be established to assure its effectiveness (Garcia-Garduño, 2003).

The first step is to determine the main objective for applying the feedback form, since it can be used to assess the administrative sphere as well as faculty's teaching performance and student learning (Ory, 1990). One of the most important goals of the evaluation centered in student feedback is to give teachers a more deep understanding of the effectiveness of their teaching methods. According to Stake (2006), a comprehensive evaluation should highlight both positive and negative aspects in teaching practices. Therefore, the author considers the evaluation as participatory when it summons those involved in the process to actively engage, in a thoughtful manner, in the activity.

The tensions surrounding the classroom in the contemporary university bring about constant changes in the ways of teaching and demand a better comprehension of the teaching-learning process and how the relationship between professors and students affects it. As stated by Krasilchik (2009), teachers focus primarily in the subject they teach, which is desirable, but only if they do not lose sight of students, those who will receive such teachings. For that reason, the ultimate goal of participatory evaluation is to give students a voice in a systematic and organized way.

In the past, our University adopted an institutional evaluation system through online surveys distributed in all Colleges and Institutes. Nevertheless, due to low participation rates, this evaluation method was extinguished. In fact, the research literature shows this as a commun phenomenal: undergraduate students don't usually take part in online surveys to evaluate their teachers and courses (Avery et al. 2006, Adams \& Umbach 2012), although higher participation rates can be achieved when universities divulge the importance of student engagement in the evaluation process (Young et al. 2018). Actualy, in our College the online survey system has been currently used to classify the data obtained and, thus, have immediate results.

This study aims to reflect on some aspects that have to be considered when this type of student evaluation of teaching methods is institutionally applied, especially when these evaluations are used as criteria to improve teaching effectiveness. It is already documented that the result of the student ratings is dependent on the undergraduate course and discipline evaluated (Uttl \& Smibert 2017). Finally, our paper discusses the experience of one 
particular faculty member, responsible for sociology discipline as a component of curricular structure in different Biological and Engineering undergraduate courses.

\section{Method}

The following data were obtained from feedback forms. The questionnare was divided by two parts and each part focused on a different evaluation object: 1) the discipline and how it is positioned in the curricular structure discipline evaluation) and 2) the individual faculty member's teaching efficacy (professor evaluation). As it is clear, these two different aspects structured the entire evaluation process, because it stimulates students and encourages them to formulate organized answers. Furthermore, by separating these different aspects of the teaching-learning process, students are allowed to elaborate deeper observations on each theme. In fact, this was one of the main objectives when we adopted this separation method in the structure of the form: by allowing students to focus specifically on each theme, they can reveal how they understand the division itself while answering each question.

Table 1 displays the individual questions, all concerning one same teacher who is responsible for the sociology discipline in three different undergraduate courses: Animal Science, Food Engineering and Veterinary Medicine. The questions involving discipline (1 to 3 ) and professor (4 to 7) evaluations were built in a multiple-choice format with five options: very poor ( 1 point), poor ( 2 points), fair ( 3 points), good ( 4 points) and excellent (5 points). From this configuration a quantitative analysis was carried out to identify the possible effects of the discipline and undergraduate courses in the student evaluation of the professor. The questionnares were anonymously applied by an online survey platform at the end of the semester. The data collected is the result of 480 student evaluations (160/course).

Table 1. Questions used to Student Evaluation of Teaching.

\begin{tabular}{ll}
\hline $\mathbf{N}$ & \multicolumn{1}{c}{ Questions } \\
\hline 1 & Is there integration of the discipline with the others of the course? \\
2 & Is the discipline important to your higher education? \\
3 & Are the prerequisites necessary to follow the discipline sufficient? \\
4 & Have the contents been clearly taught? \\
5 & Was the evaluation coherent with the topics presented in the classes? \\
6 & Did the professor stimulate your critical thinking? \\
7 & Did the teaching methods captured your interest?
\end{tabular}

1 to $3=$ Discipline, 4 to $7=$ Professor. 


\section{Results}

Considering discipline and professor evaluations, Animal Science, Food Engineering and Veterinary Medicine students assessed the Social Sciences teacher's performance as "fair", as shown by the following data: $3.7 \pm 0.4,3.3 \pm 0.5$ e $3.8 \pm 0.4$, respectively. Figure 1 displays the score means of questions referring to the discipline assessment (questions 1 to 3 ) and individual teaching efficacy (questions 4 to 7) for each undergraduate course. Regarding the professor evaluation, students from all three courses considered it as "good", as shown by the following average scores: $4.0 \pm 0.4,4.1 \pm 0.5$ e $4.4 \pm 0.4$ for Animal Science, Food Engineering and Veterinary Medicine, respectively. When it comes to discipline assessment, Animal Science and Veterinary Medicine students considered the discipline as "fair": $3.4 \pm 0.2$ e $3.4 \pm 0.1$, respectively. On the other hand, Food Engineering students considered the discipline as "bad", with an average score of $2.4 \pm 0.3$. This lower results were due to the fact that most students felt that the Sociology discipline did not really fit into their curricular structure (question 1).
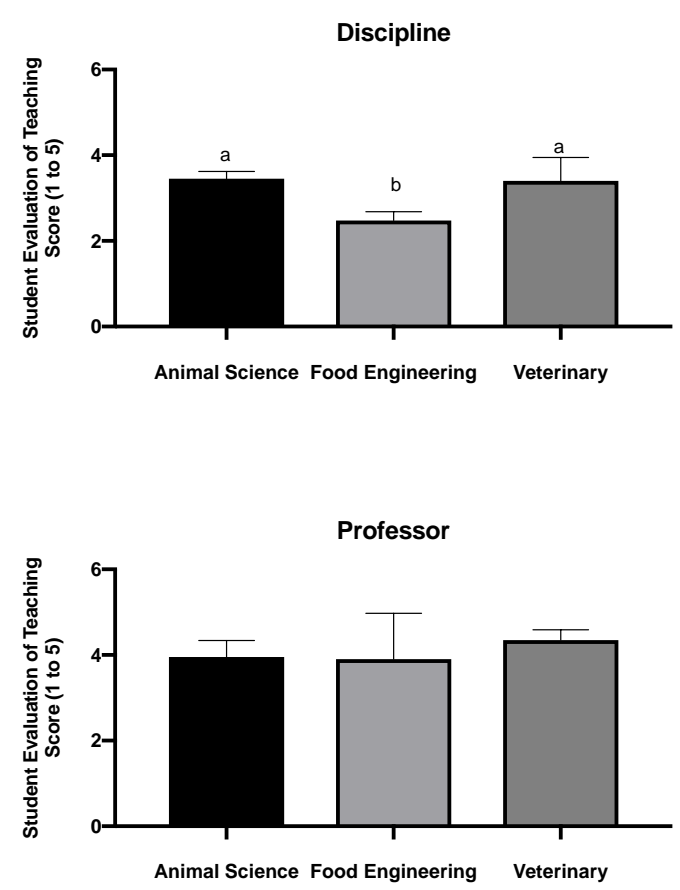

Figure 1. Means \pm SEM of Student Evaluation of Teaching Score;

$1=$ Very Poor, 2=Poor, 3=Fair, 4=Good, 5=Excellent.

Different letters $=P<0.05$. 


\section{Discussion}

Our preliminary study indicates that student evaluation of teaching could be institutionally applied to promote a diagnosis about teacher performance. The participation of the students in this process demands the understanding of how students see their classroom, their teacher's role in their education process and their particular way of accumulating knowledge and establishing relations between such knowledge and their own discoveries. It is also very relevant the perception that the students have about the impact that an evaluation system can have on the group of their teachers. However, some factors should be considered when the purpose of the institution is to use student evaluation as one of the criteria for promoting the teaching career.

One particular factor has to be considered when it comes to producing the feedback forms and the interpretation of the results. Usually questionnaires are composed by questions related to teacher's performance in the classroom and other questions that involve the relevance of the discipline within the curricular structure. According to our results, students from all three undergraduate courses rated the professor as "fair". However, these results do not entirely reflect teacher's performance, since they derive from an overall analysis of the data collected. Furthermore, once we analysed these results by separating professor evaluation from discipline evaluation, students from all three undergraduate courses considered teacher's performance as "good", while the results concerning discipline varied according to each undergraduate course. Animal Science and Veterinary Medicine students considered discipline as "fair", while Food Engineering students considered it as "poor". The results emphasize something already pointed out by the research literature: many factors can affect the results of student ratings, especially when it comes to assessment of teacher's performance (Kulik 2001, Beran \& Violato 2005, Uttl \& Smibert 2017).

Another important factor to be considered refers to the discipline and/or undergraduate course. The Social Science disciplines (in this case, Sociology) as a component of curricular structure of Biological the Engineering courses have been the focus of the present study because of its interdisciplinary character. It is clear that even if Food Engineering students rated teacher's effetiveness as "good", they do not believe that this discipline is important to their education or professional goals, since the discipline doesn't openly relates to others in the Food Engineering curriculum. This shows that student evaluation can be also used to reformulate pedagogical projects (Steyn et al. 2018).

This research show that higher education institutions can use the student ratings for various purposes using a single questionnaire. However, the questions elaborated for each purpose should be analyzed separately. Questions involving the discipline as part of the curricular structure should be avoided when student ratings are used to measure teaching effectiveness. 
Finally, the results obtained may lead to the elaboration of an institutional evaluation method based on student evaluation of teaching. This evaluation method can also create for faculty members moments of reflection and self-evaluation, allowing them to define what kind of changes and improvements could be implemented on a day by day basis. However, the evaluation of the discipline and the performance of the teacher must be considered separately.

\section{References}

Adams, M.J.D., \& Umbach P.D. (2012). Nonresponse and online student evaluations of teaching: Understanding the influence of salience, fatigue, and academic environments. Research in Higher Education, 53(5), 576-591.

Avery, R.J., Bryant, W.K., Mathios, A., Kang, H., \& Bell, D. (2006). Eletronic course evaluationsNonresponse and online student evaluations: understanding the influence of Does an online delivery system influence student evaluations?. The Journal of Economic Education, 37(1), 21-37.

Beran, T., \& Violato C. (2005). Ratings of university teacher instruction: How much do student and course characteristics really matter?. Assessment and Evaluation in Higher Education, 30(6), 593-601.

García-Garduño, J.M. (2003). Diez consejos para hacer fracasar la implantación de um sistema de evaluación de la docencia. In: Rueda, M., Diaz-Barriga, F., \& Pontones M. (Eds.). Evaluar para comprender mejorar la docencia em la educación superior. México: Universidad Autónoma Metropolitana.

Krasilchik, M. (2009). Docência no Ensino Superior: Tensões e Mudanças. In: Pimenta, S.G., Almeida M.I. Pedagogia Universitária, Brazil: Edusp.

Kulik, J.A. (2001). Student ratings: Validity, utility, and controversy. New Directions of Institutional Research, 109, 9-25.

Ory J.C. (1990). Student ratings of instruction: ethics and practice. In: Theall M., Franklin J. (Eds.). Student ratings of instruction: issues for improving practice, new directions for teaching and learning. San Francisco, EUA.

Stake, R. (2006). Evaluación comprensiva y evaluación basada en estándares. Graó, Spain.

Serrano, E.D., \& Rueda, M. (2001). Participación de académicos y estudiantes em la evaluación de la docencia. Perfiles Educativos, XXIII (93).

Steyn, C., Davies, C., \& Sambo, A. (2018). Eliciting student feedback for course development: The application of a qualitative course evaluation tool among business research students. Assessment and Evaluation in Higher Education, 44(1), 11-24.

Uttl, B., \& Smibert, D. (2017). Student evaluations of teaching: Teaching quantitative courses can be hazardous to one's carrer. Peer J, 5:e3299 https://doi.org/10.7717/peerj.3299

Young, K., Joines, J., Standish, T., \& Gallagher, V. (2018). Student evalations of teaching: The impact of faculty procedures on response rates. Assessment and Evaluation in Higher Education, 44(1), 37-49. 